\title{
Pediatric ulcerative colitis: current treatment approaches including role of infliximab
}

\author{
This article was published in the following Dove Press journal: \\ Biologics:Targets and Therapy \\ 2 June 2012 \\ Number of times this article has been viewed
}

\author{
Gia M Bradley \\ Maria Oliva-Hemker \\ Division of Pediatric \\ Gastroenterology and Nutrition, \\ Johns Hopkins University School \\ of Medicine, Baltimore, MD, USA
}

Correspondence: Maria Oliva-Hemker 600 N Wolfe Street, Brady 320,

Baltimore, MD 2/287-263।, USA

Tel + I 4109558769

Fax + | 410955 I464

Email moliva@jhmi.edu

\begin{abstract}
Ulcerative colitis is a chronic inflammatory bowel disease that can lead to derangements in the growth, nutritional status, and psychosocial development of affected children. There are several medical options for the induction and maintenance of disease remission, but the benefits of these medications need to be carefully weighed against the risks, especially in the pediatric population. As the etiology of the disease has become increasingly understood, newer therapeutic alternatives have arisen in the form of biologic therapies, which are monoclonal antibodies targeted to a specific protein or receptor. This review will discuss the classical treatments for children with ulcerative colitis, including 5-aminosalicylates, corticosteroids, thiopurine immunomodulators, and calcineurin inhibitors, with a particular focus on the newer class of anti-tumor necrosis factor- $\alpha$ agents.
\end{abstract}

Keywords: 5-aminosalicylates, anti-tumor necrosis factor- $\alpha$ agents, corticosteroids, cyclosporine, inflammatory bowel disease, thiopurine immunomodulators

\section{Introduction}

Inflammatory bowel disease (IBD) is the term used to describe idiopathic disorders associated with chronic inflammation of the gastrointestinal tract and includes Crohn's disease (CD) and ulcerative colitis (UC). ${ }^{1}$ It has recently been estimated that over 1 million people in the United States are affected by IBD, with up to $25 \%$ of these individuals being diagnosed before 20 years of age. ${ }^{2}$ This review focuses on UC, which is a disease marked by mucosal inflammation that generally begins in the rectum and involves a variable extent of proximal colon. ${ }^{1}$ A proper diagnosis of UC requires the combination of a detailed clinical history, physical examination, radiographic features, endoscopic evaluation, and tissue histology. While the pathogenesis of UC is not fully understood, genetic, immunologic, and environmental factors are thought to play a role.

UC in children has several distinct features from the disease seen in adults. Common presenting symptoms of pediatric UC include diarrhea, hematochezia, abdominal pain, and weight loss; however, interestingly, constipation can also be an early symptom. . $^{3,4}$ Adults often have disease that is limited to the rectosigmoid area of the colon, but more than $80 \%$ of children have pancolitis. ${ }^{3}$ Additionally, UC appears to manifest more aggressively in children with moderate-to-severe symptoms that require escalation of medical and surgical therapies. A retrospective review of children and adults with UC who underwent total proctocolectomy found that the duration of symptoms before surgery was significantly shorter and the disease distribution significantly more extensive in the pediatric patients. ${ }^{5}$ 
Goals of therapy for pediatric UC include induction and maintenance of disease remission, prevention of cancer of the affected bowel, improvement in quality of life, and facilitation of normal growth and development. ${ }^{6}$ Surgery, including proctocolectomy with ileal pouch-anal anastomosis, can be curative. However, surgery is not without its complications, including chronic pouchitis and fecal incontinence, so medical therapies are used to acutely induce remission of symptoms and then maintain long-term remission. ${ }^{7}$ As shown in Table 1, pharmacologic therapy for UC includes the following categories of medications: 5-aminosalicylates (5-ASAs), corticosteroids, thiopurine immunomodulators, calcineurin inhibitors, antibiotics, probiotics, and anti-tumor necrosis factor (TNF)- $\alpha$ agents. Biologic therapies, including anti-TNF- $\alpha$ agents, are an expanding class of medications that offer exciting new treatment options for UC since they target unique pathways within the pathogenesis of the disease. There is little rationale in UC for a top-down approach to treatment, where immunomodulators and anti-TNF- $\alpha$ agents are instituted much earlier in the disease course; instead, most patients are treated with an accelerated step-up approach, where medications are

Table I Classes of medications used in the management of pediatric ulcerative colitis

\begin{tabular}{|c|c|c|}
\hline Medication class & Clinical indications & Common side effects \\
\hline 5-aminosalicylates & $\begin{array}{l}\text { Mild-to-moderate } \\
\text { disease }\end{array}$ & $\begin{array}{l}\text { Headaches, } \\
\text { nausea, diarrhea, } \\
\text { photosensitivity }\end{array}$ \\
\hline Corticosteroids & $\begin{array}{l}\text { Acute } \\
\text { moderate-to-severe } \\
\text { disease }\end{array}$ & $\begin{array}{l}\text { Hyperglycemia, } \\
\text { hypertension, growth } \\
\text { failure, weight gain, } \\
\text { osteopenia, mood } \\
\text { disturbances }\end{array}$ \\
\hline $\begin{array}{l}\text { Thiopurine } \\
\text { immunomodulators }\end{array}$ & $\begin{array}{l}\text { Maintenance of } \\
\text { remission of } \\
\text { moderate-to-severe } \\
\text { disease }\end{array}$ & $\begin{array}{l}\text { Bone marrow } \\
\text { suppression, hepatitis, } \\
\text { pancreatitis, infections, } \\
\text { malaise, rashes }\end{array}$ \\
\hline $\begin{array}{l}\text { Calcineurin } \\
\text { inhibitors }\end{array}$ & $\begin{array}{l}\text { Acute severe } \\
\text { or fulminant disease }\end{array}$ & $\begin{array}{l}\text { Nephrotoxicity, } \\
\text { infections, seizures, } \\
\text { hirsutism, hypertension, } \\
\text { headaches }\end{array}$ \\
\hline Antibiotics & $\begin{array}{l}\text { Adjunctive therapy } \\
\text { for active disease; } \\
\text { pouchitis }\end{array}$ & $\begin{array}{l}\text { Specific to individual } \\
\text { antibiotics }\end{array}$ \\
\hline Probiotics & $\begin{array}{l}\text { Adjunctive therapy } \\
\text { for active disease; } \\
\text { recurrent pouchitis }\end{array}$ & Limited data \\
\hline Anti-TNF- $\alpha$ agents & $\begin{array}{l}\text { Induction and } \\
\text { maintenance of } \\
\text { remission of moderate- } \\
\text { to-severe disease }\end{array}$ & $\begin{array}{l}\text { Hypersensitivity } \\
\text { reactions, headaches, } \\
\text { nausea, abdominal pain, } \\
\text { infections }\end{array}$ \\
\hline
\end{tabular}

Abbreviation: TNF- $\alpha$, tumor necrosis factor- $\alpha$. prescribed in sequential order with regular assessment of the disease and adjustment of the treatment as needed to achieve remission. ${ }^{8}$ Therefore, this review will focus on the use of each of the aforementioned medication classes for pediatric UC of escalating severity.

\section{5-aminosalicylates}

5-ASAs are the first-line treatment for the induction and maintenance of remission of mild-to-moderate UC. ${ }^{9}$ They have a wide range of anti-inflammatory and immunomodulatory properties, including inhibition of 5-lipoxygenase, scavenging of reactive oxygen metabolites, and inhibition of interleukin- 1 synthesis. ${ }^{7}$ Free 5-ASA is almost completely absorbed from the stomach and proximal small intestine, so sustained-release preparations have been developed to deliver the medication to more distal sites of inflammation. Sulfasalazine has traditionally been used in UC and is composed of 5-ASA linked to sulfapyridine via a diazo bond that is cleaved by colonic bacteria. However, the sulfapyridine moiety has several dose-limiting side effects, including headaches, nausea, anorexia, and reversible oligospermia, that can be seen in approximately one-third of patients. ${ }^{10}$ Newer formulations, including mesalamine, olsalazine, and balsalazide, utilize $\mathrm{pH}$ - or time-dependent delivery systems to release higher concentrations of 5-ASA at various sites of the small intestine and colon with fewer side effects, thus allowing treatment to be tailored to the extent of the disease and the preferred method of medication administration.

In children, pharmacokinetic data are limited, so dosage recommendations are largely extrapolated from adult studies. A retrospective review of all children with IBD treated at Sainte-Justine Hospital in Montreal, Canada between 1984 and 1994 investigated the modalities of use, dosage, and safety of a particular mesalamine preparation, Asacol (Medeva Pharma Suisse, Geneva, Switzerland). ${ }^{11}$ A total of 153 children (120 CD, $33 \mathrm{UC}$ ) had been treated with this 5-ASA preparation alone or in combination with other medications. The children with UC received an average daily dose of $36-40.5 \mathrm{mg} / \mathrm{kg}$ with a significant improvement in hematocrit and decrease in sedimentation rate while on therapy. Overall, only eight of the 153 children (5.2\%) experienced side effects, with over half reporting an exacerbation of vomiting, abdominal pain, or diarrhea.

5-ASA can also be administered in the form of an enema or a suppository for management of distal colonic inflammation. A multicenter, open-label, nonrandomized study enrolled 49 children with ulcerative proctitis and treated 
them with a 5-ASA 500-mg suppository daily for 6 weeks. ${ }^{12}$ The main outcome measure was reduction in the disease activity index score, which considered stool frequency, urgency, blood in the stools, extracolonic features, and overall well-being of the patient. The study found significant reductions from baseline in the disease activity index score at weeks 3 and 6. Only four patients required dose escalation after 3 weeks due to worsening of or no change in clinical condition. Forty-one children (83.7\%) reported at least one adverse event, with $61.2 \%$ experiencing gastrointestinal symptoms such as abdominal pain, vomiting, or diarrhea; however, the majority of these side effects were mild and considered unrelated to study therapy.

\section{Corticosteroids}

Corticosteroids, such as prednisone and methylprednisolone, have been widely used in the acute treatment of moderateto-severe UC because of their powerful anti-inflammatory properties and rapidity of action. A recent multicenter, prospective, observational registry study found that $79 \%$ of children newly diagnosed with $\mathrm{UC}$ received corticosteroids in the first year of diagnosis, with the majority initiating corticosteroids within 30 days. ${ }^{13}$ These children were noted to have more severe disease activity and lower hemoglobin and serum albumin levels than children who did not receive corticosteroids.

Corticosteroids are effective in inducing disease remission, but their lack of efficacy as maintenance therapy combined with their significant side effects has prompted the need for additional long-term therapies. In the study mentioned above, $89 \%$ of the corticosteroid-treated children had either inactive or mild disease by 3 months after the start of therapy. ${ }^{13}$ However, at 1 year, $45 \%$ of children who had required early use of corticosteroids were considered corticosteroid-dependent because they needed either continuous or repeated courses of the medication. Ultimately, $5 \%$ of all corticosteroid-treated patients required colectomy within 1 year of treatment initiation, and the indication for colectomy in each case was corticosteroid-resistant disease. These results were seen despite the concomitant use of 5-ASAs in $86 \%$ of the children, thiopurine immunomodulators in $61 \%$, and infliximab (Remicade; Janssen Biotech, Horsham, PA), an anti-TNF- $\alpha$ agent, in $12 \%$. Similar results were found in a retrospective, population-based, inception cohort study performed from 1940 to $2001 .{ }^{14}$ Approximately $40 \%$ of patients with UC received their first treatment course of corticosteroids before the age of 19 years. By 30 days after corticosteroid initiation, complete disease remission was seen in $50 \%$ of children, partial remission in $29 \%$, and no response in $21 \%$. The 1-year outcomes revealed a prolonged response in 57\% of children, corticosteroid dependence in 14\%, and surgical resection in $29 \%$. The difference in surgery rates between the two studies may be related to differences in the cohort sizes, ages of the subjects, and/or practice patterns.

There is significant concern regarding corticosteroid toxicity in children because of well-recognized side effects such as hyperglycemia, hypertension, growth failure, weight gain, adrenal suppression, and mood disturbances. A retrospective review comparing preoperative major steroid-related complications in children and adults with UC found significantly higher incidences of growth failure, osteoporosis, glaucoma, and cataracts in children, with no significant differences in the preoperative total dosage of corticosteroids per body weight or body surface area. ${ }^{5}$ Therefore, corticosteroid-sparing treatment approaches are being used more readily; for example, clinicians may consider concomitant therapy with thiopurine immunomodulators or anti-TNF- $\alpha$ medications earlier in the treatment course of children with anticipated corticosteroiddependent UC. ${ }^{15}$

\section{Thiopurine immunomodulators}

Frequently used in pediatric UC for the maintenance of disease remission, the purine analogue 6-mercaptopurine (6-MP) and its prodrug, azathioprine (AZA), work by inhibiting RNA and DNA synthesis, thereby downregulating cytotoxic T-cell activity. ${ }^{7}$ A prospective, multicenter, inception cohort study found that 197 of 394 children with UC had received a thiopurine immunomodulator, and these patients had more moderate-to-severe disease at diagnosis than those who were never treated with this class of medications. ${ }^{16}$ Of the 133 patients evaluable at 1 year, $49 \%$ had corticosteroidfree inactive disease without the need for rescue therapy such as infliximab or surgery, while an additional 10\% had corticosteroid-free mild disease. A Kaplan-Meier analysis found that $73 \%$ of thiopurine immunomodulator-treated children were likely to remain free of rescue therapy at 1 year. While thiopurine immunomodulators have clear corticosteroid-sparing benefits, they are less useful for the induction of disease remission, since studies suggest that treatment for up to 3-4 months is necessary before a therapeutic response can be seen. ${ }^{17}$

Knowledge of the metabolism of thiopurine immunomodulators is paramount to enhancing their efficacy and minimizing side effects. AZA is a prodrug that, once absorbed, is rapidly converted to $6-\mathrm{MP} .^{18}$ The first intermediate metabolite of 6-MP, thioinosine monophosphate, is then 
converted to the thioguanine nucleotides (6-TGN), which mediate the cytotoxic and immunosuppressive effects of 6-MP. However, by an alternate pathway, 6-MP can be methylated by the thiopurine methyltransferase (TPMT) enzyme to 6-methylmercaptopurine (6-MMP). Little is known about the mechanistic role of 6-MMP, but genetic variability in the TPMT enzyme is responsible for the individual differences seen in the effectiveness and toxicity of thiopurine immunomodulators.

Adverse reactions associated with the use of these medications include allergic or idiosyncratic events, myelosuppression, hepatotoxicity, and malignancy. ${ }^{18}$ Allergic or idiosyncratic reactions, which include a flulike illness, malaise, fever, rash, abdominal pain, and pancreatitis, are seen in 5\%-10\% of patients and are independent of the thiopurine immunomodulator dose. Bone marrow suppression, especially leukopenia, is mediated by high levels of 6-TGN and is the most common dosedependent toxicity of thiopurine immunomodulators seen in $2.2 \%-15 \%$ of patients. Elevated levels of the metabolite 6-MMP, however, have been associated with hepatotoxicity, defined as transaminase levels greater than twice normal. In terms of malignancy potential, it has been recognized that immunosuppression in general can be associated with an increased risk of lymphoma. Specifically, a meta-analysis reviewed six studies of IBD patients treated with AZA or 6-MP and found a pooled relative risk of lymphoma of 4.18 (95\% confidence interval: $2.07-7.51) .{ }^{19}$

Assaying TPMT enzymatic activity prior to initiating a thiopurine immunomodulator can aid clinicians in selection of the optimal starting dose. ${ }^{18}$ Patients with normal-to-high enzyme activity ( $89 \%$ of individuals) can generally receive $2-2.5 \mathrm{mg} / \mathrm{kg} /$ day of AZA or $1-1.5 \mathrm{mg} / \mathrm{kg} / \mathrm{day}$ of $6-\mathrm{MP}$. Children with intermediate activity (11\% of individuals) can usually start at $30 \%-50 \%$ of the standard dose, with escalation as tolerated based on blood counts and 6-TGN concentrations. However, an alternate therapeutic agent should be considered for patients with low or absent enzyme activity ( $0.3 \%$ of individuals) because of the toxicity associated with elevated 6-TGN levels. As suggested above, 6-MP metabolite levels can be monitored throughout treatment, and a 6 -TGN level $\geq 235 \mathrm{pmol} / 8 \times 10^{8}$ red blood cells has been associated with a favorable therapeutic response. ${ }^{20}$ A retrospective review of 101 children with IBD receiving a thiopurine immunomodulator found that dose adjustment using 6-MP metabolite levels was associated with a statistically significant increased likelihood of being in remission, fewer disease exacerbations requiring hospitalization, decreased corticosteroid use, and administration of higher thiopurine immunomodulator doses. ${ }^{20}$

\section{Calcineurin inhibitors}

Calcineurin inhibitors, including cyclosporine and tacrolimus, have historically been used in the management of acute severe or fulminant colitis, especially in the setting of corticosteroid-refractory or -dependent disease. These agents work by blocking transcription of proinflammatory cytokines and inhibiting T-cell activation. They are typically used for only 3-4 months as a bridge to thiopurine immunomodulators or future colectomy because they have a limited role in the maintenance of remission. Additionally, widespread use of calcineurin inhibitors has been limited by potentially serious side effects, including nephrotoxicity, infections, seizures, hypomagnesemia, hypertension, hypertrichosis, and headaches, which may be improved by oral instead of intravenous medication administration. ${ }^{21}$

A retrospective, single-center review identified 14 children with fulminant colitis, marked by fever, severe abdominal pain, and six or more grossly bloody stools per day, that was unresponsive to intravenous methylprednisolone, total parenteral nutrition, and complete bowel rest. ${ }^{22}$ Each patient was initiated on oral cyclosporine $4-8 \mathrm{mg} / \mathrm{kg} /$ day, with adjustment of the dose to achieve whole blood trough levels of 150-300 ng/mL. Three patients underwent colectomy within 3 weeks of starting cyclosporine, but eleven patients (78\%) had a complete response within 2-9 days, with subsequent discharge from the hospital on cyclosporine and prednisone. Seven of the eleven discharged patients had a flare of their symptoms and required colectomy within 1 year of treatment with cyclosporine; only four patients (28\%) were able to avoid colectomy during the 6-month to 5-year follow-up period. No serious adverse events were reported, but five patients developed mild hypertension, four had an increase in serum creatinine, and six became mildly hirsute. More favorable outcomes were seen in a recent retrospective review from Italy describing 32 children with severe UC that was either dependent on or unresponsive to corticosteroids. ${ }^{23}$ They were treated with oral cyclosporine $(5 \mathrm{mg} / \mathrm{kg} /$ day adjusted to achieve whole blood levels of $150-250 \mathrm{ng} / \mathrm{mL}$ ) while being maintained on a 5-ASA and AZA. Twenty-eight patients $(87 \%)$ responded within $7-15$ days with a reduction in the number of stools, disappearance of visible blood, and cessation of abdominal pain. Four patients did not have an immediate response, so underwent colectomy, while five of the 28 initial responders required a colectomy after a mean period of 19.8 months. Twenty-three patients (72\%) avoided 
surgery during the mean follow-up period of 5.1 years, with no major cyclosporine-related side effects except for headaches in five patients. Together, these reviews suggest a benefit of cyclosporine in achieving rapid clinical remission and avoiding emergent colectomy in children with severe or fulminant colitis. Most initial responders will ultimately require surgery, but the procedure can occur in a more elective fashion with optimization of nutritional status and other perioperative factors.

Tacrolimus is another calcineurin inhibitor that is less frequently prescribed but can also be used in the setting of severe refractory UC. A retrospective study reviewed 46 children and young adults who were started on oral tacrolimus due to severe colitis unresponsive to intravenous corticosteroids. ${ }^{24}$ Tacrolimus was initiated at $0.1 \mathrm{mg} / \mathrm{kg} / \mathrm{dose}$ twice daily and titrated to yield trough levels of $10-15 \mathrm{ng} / \mathrm{mL}$ for induction and $5-10 \mathrm{ng} / \mathrm{mL}$ for maintenance. Prior to the initiation of tacrolimus, $67 \%$ of patients had severe disease and $33 \%$ had moderate disease. The median length of hospital stay after starting tacrolimus was 10 days, at which point only $4 \%$ of patients had severe disease, $30 \%$ had moderate disease, $50 \%$ had mild disease, and $15 \%$ were in remission. Overall, colectomies were performed in $46 \%$ of the patients; three of these procedures were performed during the initial hospitalization, six within the first 3 months of follow-up, and twelve during the remainder of the follow-up period (median 11.8 months). Common side effects included hypertension, tremor, hyperglycemia, headache, infection, and nephrotoxicity. Like cyclosporine, tacrolimus may be a useful induction agent for severe, corticosteroid-refractory $\mathrm{UC}$, but the long-term colectomy rate remains substantial, so alternative agents need to be considered.

\section{Antibiotics and probiotics}

It is theorized that IBD is caused, in part, by a dysregulated immune response to commensal intestinal flora. For this reason, antibiotics are often employed in disease management as a means of favorably altering the gut microbiome. There are limited data supporting antibiotic use in pediatric UC. However, in 2011, a systemic review was published of randomized controlled trials evaluating antibiotics in adults with IBD. ${ }^{25}$ For active UC, nine studies with 662 patients were reviewed, with each study using different antibiotics either alone or in combination. Overall, the authors found a statistically significant benefit for antibiotics inducing disease remission. Antibiotics are also frequently prescribed for the treatment of pouchitis, which is a complication seen in $20 \%-50 \%$ of patients following proctocolectomy with ileal pouch-anal anastomosis. ${ }^{26}$ Pouchitis often presents acutely with abdominal pain, diarrhea, and hematochezia, and is diagnosed based on clinical, endoscopic, and histologic features. It likely arises from an overgrowth of bacteria within the pouch, so first-line treatment includes a short course of an antibiotic such as metronidazole or ciprofloxacin.

Probiotics may be an alternate therapy for the management of recurrent or chronic pouchitis, ${ }^{26}$ but studies are also showing a role for probiotics in the induction and maintenance of remission of active UC. Probiotics are nonpathogenic bacteria normally found within the intestinal microflora that can decrease secretion of proinflammatory cytokines, increase production of anti-inflammatory cytokines, and enhance the integrity of the mucosal barrier. ${ }^{7}$ Several adult studies have recently investigated the use of various probiotic preparations, including VSL\#3, ${ }^{27,28}$ Escherichia coli Nissle $1917,{ }^{29}$ and Bifidobacterium longum, ${ }^{30}$ for the induction and maintenance of disease remission with promising results. A prospective, double-blind, placebo-controlled, 1-year study assessed the efficacy of the probiotic preparation VSL\#3 in achieving disease remission in children newly diagnosed with UC. ${ }^{31}$ Children were randomized to receive either VSL\#3 or placebo in addition to corticosteroid induction and 5-ASA maintenance therapy. In the VSL\#3 group, $92.8 \%$ of children had remission of their disease, compared to only $36.4 \%$ in the placebo group, with no reported side effects. Additionally, endoscopic and histologic scores were significantly better in the children receiving VSL\#3. While these results are encouraging, more prospective studies are needed of this and other probiotic preparations in larger numbers of children to support the benefit of probiotics in the management of pediatric UC.

\section{Anti-TNF- $\alpha$ agents Infliximab}

Treatment options for both the induction and maintenance of remission of moderate-to-severe UC have greatly improved with the introduction of the biologic agents, especially the anti-TNF- $\alpha$ medications. Infliximab is a genetically engineered chimeric immunoglobulin $\mathrm{G}_{1}$ monoclonal antibody consisting of $75 \%$ human and $25 \%$ murine sequences. ${ }^{32}$ It binds to both circulating and cell-bound forms of the proinflammatory cytokine TNF- $\alpha$, thereby neutralizing TNF- $\alpha$ and causing apoptosis of activated lymphocytes. Infliximab was first established as a treatment for $\mathrm{CD}$, but recognition that TNF- $\alpha$ is also found in the blood, colonic tissue, and stools of patients with UC led to further investigation of the use of infliximab for this disease. It has been shown to 
be effective in inducing clinical remission and reducing the need for colectomy in adults with UC resistant to 5-ASAs, corticosteroids, and thiopurine immunomodulators. ${ }^{33}$ In 2005 , the results were published from two randomized, doubleblind, placebo-controlled studies (the Active Ulcerative Colitis Trials [ACT] 1 and 2) that evaluated the efficacy of infliximab for the induction and maintenance of remission of UC in adults. ${ }^{34}$ In each study, 364 patients who had moderate-to-severe UC despite treatment with corticosteroids or thiopurine immunomodulators were randomized to receive either infliximab (5 or $10 \mathrm{mg} / \mathrm{kg}$ intravenously) or placebo at weeks 0,2 , and 6 , then every 8 weeks for a total of 46 weeks in ACT 1 or 22 weeks in ACT 2. At week 8 in ACT 1, 69\% of patients receiving $5 \mathrm{mg} / \mathrm{kg}$ of infliximab and $61 \%$ of those receiving $10 \mathrm{mg} / \mathrm{kg}$ had a clinical response, compared to $37 \%$ of patients in the placebo group. Similar results were found in ACT 2, where $64 \%$ of patients in the $5 \mathrm{mg} / \mathrm{kg}$ of infliximab group and $69 \%$ in the $10 \mathrm{mg} / \mathrm{kg}$ group had a clinical response at week 8 , compared to $29 \%$ of patients receiving placebo. Overall, significantly more patients in the infliximab group sustained this clinical response, demonstrated mucosal healing, and had greater decreases in their mean daily corticosteroid dose.

A number of single-center reports, as shown in Table 2, have reviewed the use of infliximab in the pediatric UC population under the following disease circumstances with encouraging results: fulminant colitis unresponsive to corticosteroids; an acute exacerbation of colitis; and corticosteroid-dependent or -refractory disease. ${ }^{35-43}$ In 2010 , a larger, prospective, multicenter, inception cohort study of a subgroup of children with UC enrolled in the Pediatric Inflammatory Bowel Disease Collaborative Research Group Registry identified 52 children who required treatment with infliximab. ${ }^{44}$ At diagnosis, $80 \%$ of these children had moderate or severe disease, compared to $66 \%$ of the children not receiving infliximab. Additionally, these children were more likely to have received corticosteroids or thiopurine immunomodulators by 3 months following diagnosis. Infliximab was initiated at a median time of 9 months from diagnosis because of corticosteroid-refractory disease in $63 \%$ of patients and corticosteroid-dependent disease in $35 \%$. Continuous maintenance infliximab was used in $65 \%$ of patients, episodic therapy in $21 \%$, and episodic converted to continuous maintenance therapy in $6 \%$. Follow-up at $3,6,12$, and 24 months found corticosteroid-free inactive disease as measured by physician global assessment in $12 / 47$ (26\%), 12/44 (27\%), 15/39 (38\%), and 6/28 (21\%) patients, respectively. When only patients on continuous maintenance therapy were considered, approximately $50 \%$ had corticosteroid-free inactive or mild disease at each

Table 2 Case series reporting the use of infliximab in the treatment of pediatric ulcerative colitis

\begin{tabular}{|c|c|c|c|}
\hline Authors & Study population & Outcomes measured & Conclusions \\
\hline Mamula et $\mathrm{al}^{35}$ & 9 children & $\begin{array}{l}\text { Clinical response (LCAI, PGA) } \\
\text { at } 2 \text { days and } 2 \text { weeks }\end{array}$ & $\begin{array}{l}\text { Median LCAI score decreased from II before } \\
\text { infusion to I at } 2 \text { days and } 2 \text { weeks after infusion; } \\
\text { decreased disease activity in } 7 \text { patients by PGA }\end{array}$ \\
\hline Mamula et $\mathrm{a}^{36}$ & 17 children & $\begin{array}{l}\text { Avoidance of colectomy } \\
\text { or escalation of medical therapy }\end{array}$ & $\begin{array}{l}14 \text { patients with short-term response; } \\
10 \text { of } 16 \text { patients with sustained response ( }>9 \text { months) }\end{array}$ \\
\hline Russell and $\mathrm{Katz}^{37}$ & I4 children & $\begin{array}{l}\text { Clinical response (LCAI) } \\
\text { by week } 6\end{array}$ & 9 patients with sustained decrease of LCAI to $\leq 2$ \\
\hline Eidelwein et $\mathrm{a}^{38}$ & 12 children & Clinical response (PGA) & $\begin{array}{l}9 \text { patients with complete short-term response at } 2 \text { weeks, } \\
3 \text { with partial response; } 8 \text { patients with long-term } \\
\text { response at } 6 \text { months }\end{array}$ \\
\hline Fanjiang et $\mathrm{al}^{39}$ & 27 children & $\begin{array}{l}\text { Clinical response (LCAI); } \\
\text { avoidance of colectomy and CSs }\end{array}$ & $\begin{array}{l}\text { Successful treatment in } 75 \% \text { of acutely ill and } 27 \% \\
\text { of chronically ill patients; mean follow-up } 27 \text { months }\end{array}$ \\
\hline Cucchiara et a ${ }^{40}$ & 22 children & $\begin{array}{l}\text { Clinical response (LCAI) } \\
\text { by week } 54\end{array}$ & $\begin{array}{l}12 \text { responders, } 6 \text { partial responders, } 4 \text { nonresponders; } \\
7 \text { patients required colectomy }\end{array}$ \\
\hline $\begin{array}{l}\text { McGinnis and } \\
\text { Murray }\end{array}$ & 40 children & $\begin{array}{l}\text { Clinical response } \\
\text { (Truelove and Witts criteria) }\end{array}$ & 28 responders, median follow-up 19 months \\
\hline Hyams et $\mathrm{al}^{44}$ & 52 children & Clinical response (PGA) & $\begin{array}{l}\text { CS-free inactive disease in } 26 \%, 27 \%, 38 \% \text {, and } 21 \% \\
\text { of patients at } 3,6,12 \text {, and } 24 \text { months }\end{array}$ \\
\hline Tiemi et al ${ }^{42}$ & $\begin{array}{l}21 \text { children } \\
\text { (7 UC, I4 CD) }\end{array}$ & $\begin{array}{l}\text { Clinical response } \\
\text { (clinical manifestations, disease } \\
\text { activity indices, CS use) } \\
\text { by week } 22\end{array}$ & $\begin{array}{l}\text { I8 patients in remission, } 3 \text { patients with clinical } \\
\text { improvement; significant improvement in disease activity } \\
\text { indices; } 6 \text { of } 15 \text { patients discontinued CSs }\end{array}$ \\
\hline Hyams et $\mathrm{a}^{43}$ & 60 children & $\begin{array}{l}\text { Clinical response (disease activity } \\
\text { indices) by week } 8\end{array}$ & 44 responders \\
\hline
\end{tabular}

Abbreviations: LCAI, Lichtiger colitis activity index; PGA, physician global assessment; CS, corticosteroid; UC, ulcerative colitis; CD, Crohn's disease. 
assessment point. Kaplan-Meier analysis determined the likelihood of remaining colectomy-free to be $79 \%, 75 \%$, $72 \%$, and $61 \%$ at each respective time point. Notably, no adverse events were reported. This study highlights the role of infliximab as both induction and maintenance therapy for children with moderate-to-severe UC unresponsive to or dependent on corticosteroids.

While generally safe and well tolerated, infliximab has been associated with such side effects as infusion reactions, infections, and malignancy. Infusion reactions are the most frequent complication occurring in either an acute or a delayed fashion. Acute reactions are marked by blood pressure instability, chest pain, dyspnea, and laryngospasm, while delayed hypersensitivity symptoms include fever, malaise, and arthralgias. A multicenter study of children with IBD reviewed a total of 1652 infliximab infusions given to 243 subjects over a period of 3 years. ${ }^{45}$ Overall, 40 patients experienced 60 infusion reactions, representing $16.5 \%$ of patients and $3.6 \%$ of infusions. Premedication with antipyretics, antihistamines, and/or corticosteroids did not necessarily prevent these reactions but did seem useful in avoiding subsequent ones. The development of antibodies to infliximab (human antichimeric antibodies [HACA]) has been associated with an increased risk of infusion reactions and a diminished response to infliximab itself. A 2004 retrospective review identified HACA in twelve of 34 children with IBD who had conclusive antibody testing. ${ }^{46}$ Infusion reactions occurred during $13.8 \%$ of the infusions given to children with positive HACA and only $3.6 \%$ of the infusions in those children with negative HACA. Recent studies have shown that continuous maintenance therapy with infliximab results in better outcomes because episodic therapy leads to a higher frequency of HACA development; maintenance infusions are typically given every 8 weeks, but shorter or longer intervals can be recommended on an individual basis. ${ }^{6}$ Additionally, in the study mentioned above, concomitant immunomodulatory therapy was significantly associated with a lower risk of developing HACA and protected against having a high titer of antibodies. ${ }^{46}$

Administration of infliximab is also associated with an increased susceptibility to infections, including pneumonia, abscesses, and sepsis, which have been reported in $3.9 \%$ of children with $\mathrm{CD} .{ }^{32}$ Its use is contraindicated in the setting of active tuberculosis or any other serious infection, and screening for tuberculosis prior to the initiation of therapy is recommended. As previously mentioned, immunosuppressed patients have an increased long-term risk of the development of lymphoma, but recent reports have described the association of concomitant therapy with infliximab and a thiopurine immunomodulator with the development of hepatosplenic T-cell lymphoma (HSTCL) in young patients with IBD ${ }^{47}$ The risk of developing HSTCL in this population is low $(\sim 0.05 \%)$, but this form of lymphoma has an aggressive course that is most often fatal. Clinicians are encouraged to have a high index of suspicion for HSTCL in patients on concurrent immunomodulatory therapy and to monitor routinely for such symptoms as fever, fatigue, elevation of liver enzymes, anemia, and leukopenia.

It is essential to monitor for infliximab nonresponse and loss of response in patients treated with the medication. Primary nonresponse is defined as the "lack of improvement of clinical signs and symptoms with induction therapy," suggesting that the symptoms may not due to an inflammatory disease, as with irritable bowel syndrome, or that TNF- $\alpha$ is not central to the inflammatory process. ${ }^{48}$ While primary nonresponse is not common in children, a proportion of patients who initially have an appropriate induction response to infliximab may eventually lose this response, known as secondary nonresponse. This loss of response can be due to increased drug clearance, HACA formation, a change in the pathophysiology of the inflammation, or increased symptoms not related to inflammation. If a child has a decreased duration or magnitude of response to infliximab, then the clinician can consider evaluating for HACA, increasing the dose, shortening the interval of administration, and/or adding a concomitant immunomodulator. However, if the child has a complete loss of response, then thought should be given to reevaluating the disease, switching to another anti-TNF- $\alpha$ agent as discussed below, or investigating possible surgical options.

\section{Adalimumab and certolizumab}

Adalimumab (Humira; Abbott Laboratories, Chicago, IL) is a fully humanized immunoglobulin $G_{1}$ monoclonal antibody to TNF- $\alpha$ that is generally used in children who either fail to tolerate or become intolerant to infliximab. It has recently been shown to be more effective than placebo for the induction and maintenance of remission in adults with moderate-to-severe UC, despite concomitant treatment with oral corticosteroids or thiopurine immunomodulators. ${ }^{49}$ This multicenter, double-blind, placebo-controlled trial randomly assigned 494 patients to receive either adalimumab (160 mg subcutaneously at week $0,80 \mathrm{mg}$ at week 2 , then $40 \mathrm{mg}$ every other week) or placebo. At week 8 , significantly more patients receiving adalimumab were in clinical remission $(16.5 \%)$ compared to those receiving placebo $(9.3 \%)$; 
at week 52, the results were similar, with $17.3 \%$ and $8.5 \%$ of patients in remission, respectively. Data is lacking on the use of adalimumab in pediatric UC. A small, single-center retrospective review from 2008 described ten children with IBD (7 CD, 3 UC) who had been treated with adalimumab following infliximab intolerance or failure; eight patients responded to adalimumab, while two patients required surgical management. ${ }^{50}$

Certolizumab (Cimzia; UCB, Brussels, Belgium) is a pegylated monoclonal antibody to TNF- $\alpha$ that is administered subcutaneously and has a longer half-life than the other anti-TNF- $\alpha$ agents because of its pegylated portion. ${ }^{51}$ Adult studies suggest the efficacy of certolizumab is comparable to the other anti-TNF- $\alpha$ therapies. However, the paucity of data on its use in children with IBD has led to its current consideration as only a rescue therapy in those patients who have failed treatment with other agents.

\section{Summary of the treatment approach to pediatric UC}

The treatment of pediatric UC is sequential and tailored to the severity of disease activity. ${ }^{52}$ Patients with mild-to-moderate disease are frequently initiated on a 5-ASA preparation. If they do not respond or if the disease is more moderate to severe at presentation, then a course of corticosteroids can be trialed, with transition to a thiopurine immunomodulator for maintenance therapy. Alternately, infliximab has been increasingly used as a corticosteroid-sparing agent for both the induction and maintenance of remission of moderateto-severe disease. Severe or fulminant colitis requires the prompt initiation of appropriate medical and/or surgical therapies in order to minimize morbidity. ${ }^{21}$ Intravenous corticosteroids have been the mainstay of treatment for severe UC since the first studies supporting their use were published in $1955 .{ }^{53}$ However, corticosteroid refractoriness is common in this patient population, so second-line therapies, including calcineurin inhibitors, anti-TNF- $\alpha$ agents, and surgery, need to be considered early in the treatment course.

Generation and validation of the Pediatric Ulcerative Colitis Activity Index (PUCAI) has led to a more robust definition of acute severe colitis and has allowed clinicians to better predict the outcomes of children admitted for intravenous corticosteroids, thus facilitating a more timely introduction of second-line therapies. ${ }^{54,55}$ The PUCAI score ranges from 0 to 85 , with points given to the degree of abdominal pain, amount of rectal bleeding, stool consistency, number of stools per day, presence of nocturnal stools, and activity level; a PUCAI score $\geq 65$ is consistent with severe disease activity.
In a prospective, multicenter study of 128 children with severe UC, 37 children failed intravenous corticosteroids within a mean of 10.5 days and subsequently received cyclosporine $(3 \%)$, colectomy $(8 \%)$, or infliximab $(89 \%) .{ }^{56}$ Long-term follow-up revealed that 25 of the 33 patients treated with infliximab were responders. The authors also determined that the PUCAI score on days 3 and 5 of hospitalization could be used to decide the timing of introduction of second-line therapy in these patients with severe colitis. A child with a PUCAI score $>45$ on day 3 should be prepared for secondline therapy, while a score $>65$ on day 5 should prompt initiation of that therapy. ${ }^{21}$

With the advent of anti-TNF- $\alpha$ agents, the use of calcineurin inhibitors as second-line agents has significantly decreased in the pediatric UC population because of their lack of efficacy as maintenance therapy and the toxicities associated with their use. Anti-TNF- $\alpha$ agents, especially infliximab, are effective in the acute management of severe or fulminant colitis that is unresponsive to corticosteroids; their additional utility as maintenance therapy and improved side-effect profile have made them a more favorable second-line therapy than calcineurin inhibitors. While medical therapy in the setting of severe or fulminant colitis is generally preferred in children, colectomy should also be seriously considered, especially in the presence of life-threatening hemorrhage, perforation, or peritonitis. Other standard indications for surgical intervention include the following: worsening symptoms despite maximal medical management; history of chronic corticosteroid use with significant side effects; history of long-standing, extensive disease for greater than 10 years; or delay in growth and maturation. The surgical procedure of choice in UC is a proctocolectomy with an ileal pouch-anal anastomosis, which preserves anorectal continence and has been associated with excellent long-term results. ${ }^{1,26}$

\section{Conclusions}

The treatment of pediatric UC is an expanding field due to the increased understanding of the genetic and immunological basis of the disease. Clinicians are limiting the use of corticosteroids, given their lack of efficacy as maintenance medications and significant side-effect profile, in favor of newer therapies with enhanced efficacy. Anti-TNF- $\alpha$ agents, including infliximab, offer important therapeutic alternatives because they target a specific cytokine that is essential in the pathogenesis of the disease. While promising data are arising from adult studies, more research is needed on the use of these new medications in children, including comparative studies of the multiple anti-TNF- $\alpha$ agents. Ultimately, the goals of 
the treatment of pediatric UC remain the same, and clinicians continue to aim for improved control of the disease, adequate growth, and enhanced quality of life in their patients.

\section{Disclosure}

Maria Oliva-Hemker received a research grant from Abbott Immunology. Gia M Bradley reports no conflicts of interest in this work.

\section{References}

1. Hyams JS. Inflammatory bowel disease. Pediatr Rev. 2005;26(9): 314-320

2. Cuffari C. Inflammatory bowel disease in children: a pediatrician's perspective. Minerva Pediatr. 2006;58(2):139-157.

3. Sawczenko A, Sandhu BK. Presenting features of inflammatory bowel disease in Great Britain and Ireland. Arch Dis Child. 2003;88(11):995-1000.

4. Hyams J, Davis P, Lerer T, et al. Clinical outcome of ulcerative proctitis in children. J Pediatr Gastroenterol Nutr. 1997;25(2):149-152.

5. Uchida K, Araki T, Toiyama Y, et al. Preoperative steroid-related complications in Japanese pediatric patients with ulcerative colitis. Dis Colon Rectum. 2006;49(1):74-79.

6. Carvalho R, Hyams JS. Diagnosis and management of inflammatory bowel disease in children. Semin Pediatr Surg. 2007;16(3):164-171.

7. Greifer MK, Markowitz JF. Update in the treatment of paediatric ulcerative colitis. Expert Opin Pharmacother. 2006;7(14):1907-1918.

8. Devlin SM, Panaccione R. Evolving inflammatory bowel disease treatment paradigms: top-down versus step-up. Gastroenterol Clin North Am. 2009;38(4):577-594.

9. Quiros JA, Heyman MB, Pohl JF, et al. Safety, efficacy, and pharmacokinetics of balsalazide in pediatric patients with mild-to-moderate active ulcerative colitis: results of a randomized, double-blind study. J Pediatr Gastroenterol Nutr. 2009;49(5):571-579.

10. Tolia V, Massoud N, Klotz U. Oral 5-aminosalicyclic acid in children with colonic chronic inflammatory bowel disease: clinical and pharmacokinetic experience. J Pediatr Gastroenterol Nutr. 1989;8(3):333-338.

11. D'Agata ID, Vanounou T, Seidman E. Mesalamine in pediatric inflammatory bowel disease: a 10-year experience. Inflamm Bowel Dis. 1996;2(4):229-235.

12. Heyman MB, Kierkus J, Spenard J, Shbaklo H, Giguere M. Efficacy and safety of mesalamine suppositories for treatment of ulcerative proctitis in children and adolescents. Inflamm Bowel Dis. 2010;16(11):1931-1939.

13. Hyams J, Markowitz J, Lerer T, et al. The natural history of corticosteroid therapy for ulcerative colitis in children. Clin Gastroenterol Hepatol. 2006;4(9):1118-1123.

14. Tung J, Loftus EV Jr, Freese DK, et al. A population-based study of the frequency of corticosteroid resistance and dependence in pediatric patients with Crohn's disease and ulcerative colitis. Inflamm Bowel Dis. 2006;12(12):1093-1100.

15. Oliva-Hemker M, Escher JC, Moore D, et al. Refractory inflammatory bowel disease in children. J Pediatr Gastroenterol Nutr. 2008;47(2):266-272.

16. Hyams JS, Lerer T, Mack D, et al. Outcome following thiopurine use in children with ulcerative colitis: a prospective multicenter registry study. Am J Gastroenterol. 2011;106(5):981-987.

17. Kirschner BS. Safety of azathioprine and 6-mercaptopurine in pediatric patients with inflammatory bowel disease. Gastroenterology. 1998;115(4):813-821.

18. Dubinsky MC. Azathioprine, 6-mercaptopurine in inflammatory bowel disease: pharmacology, efficacy, and safety. Clin Gastroenterol Hepatol. 2004;2(9):731-743.
19. Kandiel A, Fraser AG, Korelitz BI, Brensinger C, Lewis JD. Increased risk of lymphoma among inflammatory bowel disease patients treated with azathioprine and 6-mercaptopurine. Gut. 2005;54(8):1121-1125.

20. Banerjee S, Bishop WP. Evolution of thiopurine use in pediatric inflammatory bowel disease in an academic center. J Pediatr Gastroenterol Nutr. 2006;43(3):324-330.

21. Turner D, Travis SP, Griffiths AM, et al. Consensus for managing acute severe ulcerative colitis in children: a systematic review and joint statement from ECCO, ESPGHAN, and the Porto IBD Working Group of ESPGHAN. Am J Gastroenterol. 2011;106(4):574-588.

22. Treem WR, Cohen J, Davis PM, Justinich CJ, Hyams JS. Cyclosporine for the treatment of fulminant ulcerative colitis in children. Immediate response, long-term results, and impact on surgery. Dis Colon Rectum. 1995;38(5):474-479.

23. Castro M, Papadatou B, Ceriati E, et al. Role of cyclosporin in preventing or delaying colectomy in children with severe ulcerative colitis. Langenbecks Arch Surg. 2007;392(2):161-164.

24. Watson S, Pensabene L, Mitchell P, Bousvaros A. Outcomes and adverse events in children and young adults undergoing tacrolimus therapy for steroid-refractory colitis. Inflamm Bowel Dis. 2011;17(1):22-29.

25. Khan KJ, Ullman TA, Ford AC, et al. Antibiotic therapy in inflammatory bowel disease: a systematic review and meta-analysis. $\mathrm{Am} J$ Gastroenterol. 2011;106(4):661-673.

26. Alexander F. Complications of ileal pouch anal anastomosis. Semin Pediatr Surg. 2007;16(3):200-204.

27. Sood A, Midha V, Makharia GK, et al. The probiotic preparation, VSL\#3 induces remission in patients with mild-to-moderately active ulcerative colitis. Clin Gastroenterol Hepatol. 2009;7(11): $1202-1209$.

28. Tursi A, Brandimarte G, Papa A, et al. Treatment of relapsing mild-tomoderate ulcerative colitis with the probiotic VSL\#3 as adjunctive to a standard pharmaceutical treatment: a double-blind, randomized, placebocontrolled study. Am J Gastroenterol. 2010;105(10):2218-2227.

29. Matthes H, Krummenerl T, Giensch M, Wolff C, Schulze J. Clinical trial: probiotic treatment of acute distal ulcerative colitis with rectally administered Escherichia coli Nissle 1917 (EcN). BMC Complement Altern Med. 2010;10:13.

30. Fujimori S, Gudis K, Mitsui K, et al. A randomized controlled trial on the efficacy of synbiotic versus probiotic or prebiotic treatment to improve the quality of life in patients with ulcerative colitis. Nutrition. 2009;25(5):520-525.

31. Miele E, Pascarella F, Giannetti E, Quaglietta L, Baldassano RN, Staiano A. Effect of a probiotic preparation (VSL\#3) on induction and maintenance of remission in children with ulcerative colitis. $\mathrm{Am} \mathrm{J}$ Gastroenterol. 2009;104(2):437-443.

32. Veres G, Baldassano RN, Mamula P. Infliximab therapy in children and adolescents with inflammatory bowel disease. Drugs. 2007;67(12):1703-1723.

33. Lawson MM, Thomas AG, Akobeng AK. Tumour necrosis factor alpha blocking agents for induction of remission in ulcerative colitis. Cochrane Database Syst Rev. 2006;3:CD005112.

34. Rutgeerts P, Sandborn WJ, Feagan BG, et al. Infliximab for induction and maintenance therapy for ulcerative colitis. $N$ Engl $J$ Med. 2005;353(23):2462-2476.

35. Mamula P, Markowitz JE, Brown KA, Hurd LB, Piccoli DA, Baldassano RN. Infliximab as a novel therapy for pediatric ulcerative colitis. J Pediatr Gastroenterol Nutr. 2002;34(3):307-311.

36. Mamula P, Markowitz JE, Cohen LJ, von Allmen D, Baldassano RN. Infliximab in pediatric ulcerative colitis: two-year follow-up. J Pediatr Gastroenterol Nutr. 2004;38(3):298-301.

37. Russell GH, Katz AJ. Infliximab is effective in acute but not chronic childhood ulcerative colitis. $J$ Pediatr Gastroenterol Nutr. 2004;39(2):166-170.

38. Eidelwein AP, Cuffari C, Abadom V, Oliva-Hemker M. Infliximab efficacy in pediatric ulcerative colitis. Inflamm Bowel Dis. 2005;11(3): 213-218. 
39. Fanjiang G, Russell GH, Katz AJ. Short- and long-term response to and weaning from infliximab therapy in pediatric ulcerative colitis. J Pediatr Gastroenterol Nutr. 2007;44(3):312-317.

40. Cucchiara S, Romeo E, Viola F, et al. Infliximab for pediatric ulcerative colitis: a retrospective Italian multicenter study. Dig Liver Dis. 2008; 40 Suppl 2:S260-S264.

41. McGinnis JK, Murray KF. Infliximab for ulcerative colitis in children and adolescents. J Clin Gastroenterol. 2008;42(8):875-879.

42. Tiemi J, Komati S, Sdepanian VL. Effectiveness of infliximab in Brazilian children and adolescents with Crohn disease and ulcerative colitis according to clinical manifestations, activity indices of inflammatory bowel disease, and corticosteroid use. J Pediatr Gastroenterol Nutr. 2010;50(6):628-633.

43. Hyams J, Damaraju L, Blank M, et al. Induction and maintenance therapy with infliximab for children with moderate to severe ulcerative colitis. Clin Gastroenterol Hepatol. 2012;10(4):391-399.

44. Hyams JS, Lerer T, Griffiths A, et al. Outcome following infliximab therapy in children with ulcerative colitis. Am J Gastroenterol. 2010;105(6):1430-1436.

45. Jacobstein DA, Markowitz JE, Kirschner BS, et al. Premedication and infusion reactions with infliximab: results from a pediatric inflammatory bowel disease consortium. Inflamm Bowel Dis. 2005;11(5):442-446.

46. Miele E, Markowitz JE, Mamula P, Baldassano RN. Human antichimeric antibody in children and young adults with inflammatory bowel disease receiving infliximab. J Pediatr Gastroenterol Nutr. 2004;38(5):502-508.

47. Rosh JR, Gross T, Mamula P, Griffiths A, Hyams J. Hepatosplenic T-cell lymphoma in adolescents and young adults with Crohn's disease: a cautionary tale? Inflamm Bowel Dis. 2007;13(8):1024-1030.
48. Yanai H, Hanauer SB. Assessing response and loss of response to biological therapies in IBD. Am J Gastroenterol. 2011;106(4):685-698.

49. Sandborn WJ, van Assche G, Reinisch W, et al. Adalimumab induces and maintains clinical remission in patients with moderate-to-severe ulcerative colitis. Gastroenterology. 2012;142(2):257-265.

50. Noe JD, Pfefferkorn M. Short-term response to adalimumab in childhood inflammatory bowel disease. Inflamm Bowel Dis. 2008;14(12):1683-1687.

51. Bousvaros A. Use of immunomodulators and biologic therapies in children with inflammatory bowel disease. Expert Rev Clin Immunol. 2010;6(4):659-666.

52. Blonski W, Buchner AM, Lichtenstein GR. Inflammatory bowel disease therapy: current state-of-the-art. Curr Opin Gastroenterol. 2011;27(4):346-357.

53. Truelove SC, Witts LJ. Cortisone in ulcerative colitis; final report on a therapeutic trial. Br Med J. 1955;2(4947):1041-1048.

54. Turner D, Otley AR, Mack D, et al. Development, validation, and evaluation of a pediatric ulcerative colitis activity index: a prospective multicenter study. Gastroenterology. 2007;133(2):423-432.

55. Turner D, Hyams J, Markowitz J, et al. Appraisal of the pediatric ulcerative colitis activity index (PUCAI). Inflamm Bowel Dis. 2009;15(8):1218-1223.

56. Turner D, Mack D, Leleiko N, et al. Severe pediatric ulcerative colitis: a prospective multicenter study of outcomes and predictors of response. Gastroenterology. 2010;138(7):2282-2291.
Biologics: Targets \& Therapy

\section{Publish your work in this journal}

Biologics: Targets \& Therapy is an international, peer-reviewed journal focusing on the patho-physiological rationale for and clinical application of Biologic agents in the management of autoimmune diseases, cancers or other pathologies where a molecular target can be identified. This journal is indexed on PubMed Central, CAS, EMBase, Scopus

\section{Dovepress}

and the Elsevier Bibliographic databases. The manuscript management system is completely online and includes a very quick and fair peerreview system, which is all easy to use. Visit http://www.dovepress com/testimonials.php to read real quotes from published authors. 